\title{
Spinal brucellosis: a personal experience of nine patients and a review of the literature
}

\author{
F Faria and F Viegas \\ Spinal Cord Injuries Department, Centro de Medicina de Reabilitação, 2675 Estoril, Portugal
}

\begin{abstract}
A retrospective study of patients with spinal brucellosis was performed to outline the syndrome and its treatment, including rehabilitation. The patients were admitted to our spinal cord unit between 1975 and 1990. We studied nine patients (five males and four females), with a mean age of 49 years, and not belonging to any professional risk group except for one patient. At discharge, there was an improvement in sphincter control, execution of daily living activities and walking ability. No improvement was found in the neurological status. In conclusion we emphasize the importance of the prevention, early diagnosis and adequate treatment of the condition to minimise the neurological sequelae.
\end{abstract}

Keywords: spinal lesion; paraplegia; tetraplegia; brucellosis; treatment; outcome

\section{Introduction}

Brucellosis is an anthropozoonosis caused by a Gram negative bacilli of the genus Brucella. ${ }^{1-3}$ Infection in man is mainly caused by ingestion of contaminated meat or dairy products, and rarely by percutaneous, conjunctival or aerosol inhalation. The musculoskeletal system is frequently affected and the spine is the most common site of bone brucellosis. ${ }^{3-6}$ The radiological signs are usually disc collapse, sclerosis, osteophytosis and paraspinal abcesses. ${ }^{3,7}$

The main diagnostic problem of spinal brucellosis is differentiation from other infectious processes, particularly tuberculosis, which is also very frequent in Portugal..$^{2-3,6,8}$

The relevance of the spinal lesion comes not only from its frequency but also because of the potential morbidity capable of causing important functional incapacity. ${ }^{3,6,8,9}$ We have had in our unit several patients with brucellosis with severe neurological sequelae. Because of the few references in the literature on this subject, we performed this study to evaluate in particular the results of rehabilitation in these patients.

\section{Patients and methods}

We review the clinical records of nine patients admitted to the spinal cord lesion unit between 1975 and 1990 who presented with a diagnosis of brucellosis. This diagnosis was confirmed prior to hospital admittance by laboratory findings, by isolation of the bacteria or by serological tests.

\section{Results}

We found an equal distribution between sexes (five males and four females) with a mean age of 49 years (varying between 30 and 70 years). Eight patients came from rural areas but only one had an occupation where he could be considered to be at risk (a shepherd).

The types of lesion were classified as follows: five patients with granuloma, two with spondylodiscitis, and two with an epidural abcess.

The location was the thoracic spine in five patients and the cervical spine in four.

The initial symptomatology was neurological in five patients, with muscular weakness, altered sensibility and/or sphincter incontinence. In the other four patients these symptoms were preceded by fever, sweating, asthenia and myalgia.

Prior to their admittance to our unit, eight patients had had decompressive laminectomy. The neurological status of the patients remained the same during hospitalisation: five had presented with spastic tetraparesis, three with spastic paraparesis, and one with a Brown-Séquard syndrome.

On admission, four patients had normal sphincter control and five were incontinent: three had urgency of micturition and two had a Foley catheter. As part of the rehabilitation programme, sphincter training was started with the following results: two obtained efficient training and three continued with urgency. All five developed efficient intestinal function.

Regarding activities of daily living, only one patient was totally independent on admission, two were functional in a wheelchair, and five needed assistance for such activities as transferring, feeding, going to toilet, dressing and bathing. After rehabilitation, six patients became functionally independent, and two still required some help (one patient only for cutting food, and the other also for bathing and dressing).

Prior to the rehabilitation programme, six patients required to use a wheelchair, two needed walking aids and one was independent with walking. At discharge, three patients who used a wheelchair could now walk with walking aids. 


\section{Discussion}

This retrospective study was performed to evaluate the profile and the functional outcome of patients with spinal brucellosis. Nine patients had this condition, five males and four females. The mean age of the population was 49 years, which accords with reports from other authors. ${ }^{3,6,10}$ Contrary to the findings in the literature,$^{2-4,8}$ we did not find a greater incidence in males or special involvement of the lumbar spine.

In five patients, the condition of brucellosis presented with neurological signs, which delayed the diagnosis and treatment, thus unfortunately leading to irreversible sequelae. The other four patients had clinical evidence of brucellosis and were submitted to antibiotic therapy which, however, was inadequate. Early diagnosis and prompt treatment with antibrucellar chemotherapy are known to be effective..$^{4,5,10,11}$

Surgical decompression is rarely needed ${ }^{11,12}$ but in our series, eight out of nine patients underwent laminectomy prior to admittance to our unit. There was no alteration of the neurological status during hospitalisation, as all had a complete spinal lesion.

As a result of the rehabilitation programme sphincter control improved or at least the patients developed efficient training, which allowed them to pursue a more active social life.

Six out of the nine patients became functionally independent for the activities of daily living. All improved concerning mobility except for one patient who was already independent in walking; but three of the patients remained wheelchair bound and could propel it.

To conclude, we emphasise the importance of preventing this disease. Its eradication can only be achieved by eradicating infected animals, thus eliminating the reservoir. On the other hand, early diagnosis followed by adequate treatment can prevent serious neurological sequelae.

\section{References}

1 Salata RA, Ravdin JI. Brucella species. In: Mandell GL, Douglas RG, Bennet JE (eds). Principles and Practice of Infectious Diseases. New York: Willey, 1985, pp 1283-1290.

2 Sharif HS et al. Brucellar and tuberculous spondylitis: comparative imaging features; Radiology 1989; 171: 419-425.

3 Roux H, Peloux Y, Gaborit P, Bonnefoy-Cudraz M. Les manifestations ostéo-articularies de la Brucellose. Enc Med Chir, Appareil Locomoteur, 14182 A10, 9- 1983, Paris.

4 Ariza J et al. Brucellar spondylitis: a detailed analysis based on current findings. Rev Infect Dis 1985; 7: 656-664.

5 Lifeso RM, Harder E, McCorkell SJ. Spinal brucellosis; J Bone Joint Surg Br 1985; 67: 345-351.

6 Lopes $\mathrm{C}$ et al. Espondilite Brucélica - quatro anos de experiência. Acta Médica Port 1992; 5: 419-423.

7 Glenn L et al. Brucellosis of the spine; Spine 1987; 123: 414-416.

8 Mousa A et al. Osteoarticular complications of brucellosis: a study of 169 cases. Rev Infect Dis 1987; 9: 531-543.

9 Navas AF et al. Complicaciones neurológicas en la espondilitis brucellar. Rev Clin Esp 1979; 152: 131-135.

10 Rajapakse CNA et al. Spinal brucellosis; Br J Rheum 1987; 26 : 28-31.

11 Young EJ: Human brucellosis. Rev Infect Dis 1983; 5: 821-842.

12 Kelly PJ, Martin WJ, Schirger A, Week CA. Brucellosis of the bones and joints; JAMA 1960; 174: 347-353. 